\title{
Analysis of the Misconceptions about Aid and Hepatitis among the Student of Nishtar Medical College Multan: A Study of Knowledge, Aptitude, and Perspective
}

\author{
Abdul Ghafoor Awan ${ }^{1}$, Ammarah Ghafoor ${ }^{2}$, Muhammad Tayyab Ghafooor ${ }^{3}$ \\ ${ }^{1}$ Dean, Institute of Southern Punjab, Multan, PAKISTAN \\ ${ }^{2}$ Nishtar Medical College, Multan, PAKISTAN \\ ${ }^{3}$ Multan Medical and Dental College, Multan, PAKISTAN
}

\begin{abstract}
Introduction: A number of evaluations regarding awareness among people about modes of transmission, sources of transmission and vaccination against HBV, HCV, and HIV have been carried out but very few of them have specifically focused medical students. This study reflects the degree of awareness of 3rd year MBBS students on these issues and their vaccination status. It also depicts whether medical students are afraid of examining patients afflicted with these diseases or not.

Objectives of study: To determine the knowledge and aptitude of medical students about various aspects of $\mathrm{HBV}$, $\mathrm{HCV}$, and HIV diseases.

Data \& Methodology: We used primary data in this study which is cross-sectional in study. The data was collected through a structured questionnaire. As many 130 third years students of MBBS students of Nishtar Medical College were selected as the sample of the study. The field survey method was used to collect the data. Statistical description methods such as frequency distribution, graphs, and tables were used to explain and analyze the data.

Findings and Results: Our study evidence shows that 28.4 percent students possessed complete knowledge about the modes of transmission of HBV, HCV, and HIV while 70.7 percent have incomplete knowledge whereas 0.07 percent of the students have no knowledge about these diseases. Similarly, 60 percent of the students have no fear about the examinations of the patients suffering these diseases while 40 percent were afraid about them. Regarding the availability of vaccination against HBV, HCV and HIV 80.7 percent have knowledge about HBV, 42.3 percent about $\mathrm{HCV}$ and 16.9 percent about HIV. Our results show that 81.5 percent sampling students were vaccinated against HBV while 19.5 percent were not. Due to lack of awareness, negligence, etc.

Conclusions: Our study concludes that majority of sampling students having full knowledge about these fatal diseases were lower than expected and it is, therefore, recommended that an awareness campaign should be launched so that students should be well-acquainted about the fatal impact of HBV, HCV, and HIV. Special seminars or workshops should be arranged to educate and train these students so that they may be able to cope with these diseases effectively after completion of their education.
\end{abstract}

Key words: Modes of transmission, source of transmission, vaccination

How to Cite: Awan AG, Ghafoor A and Ghafooor MT. (2015) Analysis of the Misconceptions about Aid and Hepatitis among the Student of Nishtar Medical College Multan: A Study of Knowledge, Aptitude, and Perspective, Malaysian Journal of Medical and Biological Research, 2(2), 77-84.

This article is is licensed under a Creative Commons Attribution-NonCommercial 4.0 International License.

Attribution-NonCommercial (CC BY-NC) license lets others remix, tweak, and build upon work non-commercially, and although the new works must also

acknowledge \& be non-commercial.

\section{INTRODUCTION}

Reports of successful antiviral therapy for chronic hepatitis B virus (HBV) infection appeared three decades ago, and during the past decade, progress has accelerated dramatically. Along with progress, however, has come complexity. So much more is known now than at the dawn of the antiviral era about the protean clinical expressions of HBV infection that determining whom, when, and how to treat has become progressively more challenging.

\section{Main Research Problem}

To Analyze Knowledge, Aptitude and Perspective of general Misconceptions about Aid and Hepatitis diseases among the Students of Nishtar Medical College. Are the students well-aware the causes and treatment of these fatal diseases and if they are aware what its percentage is and if the level of awareness is low than desired what method should be used to create awareness and to change in their aptitude.

Objectives of Study

There are two main objectives of the study which are outlined as under:- 
- To determine the frequency of knowledge about the mode of transmission of HBV, HCV and HIV.

- To find out fear and misconceptions about the source of transmission among students.

\section{Scope of the Study}

The scope of the study is wide because Hepatitis B Virus is on rampage not only in Pakistan but all over the world and millions of people are suffering from it in different countries. Although the results of this study are specific but they can be generalized and the administration of different Medical Colleges in Pakistan and in other countries can take policy initiatives in the light of recommendations made in this study. Thus, the impact and scope of the study is multi-dimensional and vast and very useful for the whole medical community.

\section{What is Hepatitis B Virus?}

Hepatitis B virus (HBV) infection and its sequel are major global health problems. The natural history of hepatitis B is complex and is influenced by many factors, including age at infection, viral factors(HBV genotype, viral mutations, level of HBV replication), host factors(gender, age and immune status), and exogenous factors such as concurrent infection with other hepatotoxic viruses and alcohol. The clinical spectrum of HBV infection ranges from subclinical to acute symptomatic hepatitis or, rarely, fulminant hepatitis during acute phase and from the inactive hepatitis B surface antigen (HBsAg) carrier state to chronic hepatitis, cirrhosis, and its complications during the chronic phase. Approximately15$40 \%$ of people who develop chronic HBV infection are expected to progress to cirrhosis and end-stage liver disease. Difficulties in defining the natural history of chronic hepatitis B include the indolent course of the disease, the lack of symptoms during the early stages, and the heterogeneity of the disease. Understanding the natural history and prognosis of hepatitis $B$ is the basis for disease management and for designing better therapeutic strategies.

$\mathrm{HBV}$, a DNA virus transmitted parentally, sexually, and parentally, affects1.25 millionpersons in the United States and 350 to 400 million persons worldwide. HBV infection accounts annually for 4000 to 5500 deaths in the United States and 1 million deaths worldwide from cirrhosis, liver failure, and hepatocellular carcinoma.

Hepatitis $\mathrm{C}$ virus (HCV) infects an estimated 170 million persons worldwide and thus represents a viral pandemic, one that is five times as widespread as infection with the human immunodeficiency virus type 1 (HIV-1). The institution of blood-screening measures in developed countries has decreased the risk of transfusion-associated hepatitis to a negligible level, but new cases continue to occur mainly as a result of injection-drug use and, to a lesser degree, through other means of percutaneous or mucous-membrane exposure. Progression to chronic disease occurs in the majority of HCV-infected persons, and infection with the virus has become the main indication for liver transplantation. HCV infection also increases the number of complications in persons who are co-infected with HIV-1. Although research advances have been impeded by the inability to grow HCV easily in culture, there have been new insights into pathogenesis of the infection and improvements in treatment options. Human immunodeficiency virus/ acquired immunodeficiency syndrome (HIV/AIDS) is a disease of the human immune system caused by infection with human immunodeficiency virus (HIV).HIV is transmitted primarily via unprotected sexual intercourse (including anal and even oral sex), contaminated blood transfusions, hypodermic needles, and from mother to child during pregnancy, delivery, or breastfeeding. Some bodily fluids, such as saliva and tears, do not transmit HIV.Genetic research indicates that HIV originated in west-central Africa during the early twentieth century. AIDS was first recognized by the Centers for Disease Control and Prevention (CDC) in 1981 and its cause-HIV infection-was identified in the early part of the decade. Since its discovery, AIDS has caused nearly 30 million deaths (as of 2009). As of 2010, approximately34 million people have contracted HIV globally. AIDS is considered a pandemic - a disease outbreak which is present over a large area and is actively spreading.

\section{Methodology}

Research methodology is a set of rules and procedures which we use to analyze the data and draw results. These procedures help us to conduct a study systematically and coherently.

Nature of Study: It is a cross-sectional study and is descriptive in nature in which we have explored the attitude, fear, and perspective of medical students of third years studying at Nishtar College Multan, Pakistan. It is pertinent to mention here that Nishtar Medical College is the old and one of the biggest College and Hospital of Asia.

Sampling Technique: Sampling technique refers to the method used to choose the sample from the population. Poor sample designs can produce misleading conclusion. This technique specifies the method of selecting the sample. The most commonly used samplings are: probability random sampling and convenient sampling. We used convenient sampling method because our study is exploratory in nature and the questionnaire were filled from the students which were fellows and conveniently available in a group form. The size of sample was 130 students of MBBS studying in third year at Nishtar Medical College, Multan.

Data and Types: We used primary data in this study which was collected through a structured questionnaire. A field survey method was used to collect the data. Face-to-face interviews were conducted to record the response of target group of students. 
Estimation Techniques: Basic statistical techniques like frequency distribution, charts, and tables were used to explain and analyze data. These techniques are mostly used in exploratory studies to highlight specific phenomenon.

\section{DatA ANALYsis}

The findings and results of our research are stated in the following Tables.

Table 1: Frequency distribution table showing knowledge of students about modes of Transmission of HBV, HCV, and HIV (Total Number of Students)

\begin{tabular}{|c|c|c|c|c|c|c|}
\hline & \multicolumn{2}{|c|}{ COMPLETE } & \multicolumn{2}{c|}{ INCOMPLETE } & \multicolumn{2}{c|}{ NO KNOWLEDGE } \\
\hline & Number of students & $\%$ & Number of students. & $\%$ & Number of students & $\%$ \\
\hline KNOWLEDGE & 37 & 28.4 & 92 & 70.7 & 1 & 0.007 \\
\hline
\end{tabular}

Table 1 shows that out of 37, 28 percent students possess complete knowledge about HBV, HCV and HIV while 70.7 percent students have incomplete knowledge whereas only one student had $\mathrm{n}$ knowledge about it. The same is shown in the Figure.

Figure 1: Ration of students having knowledge about HBV, HCV \& HIV

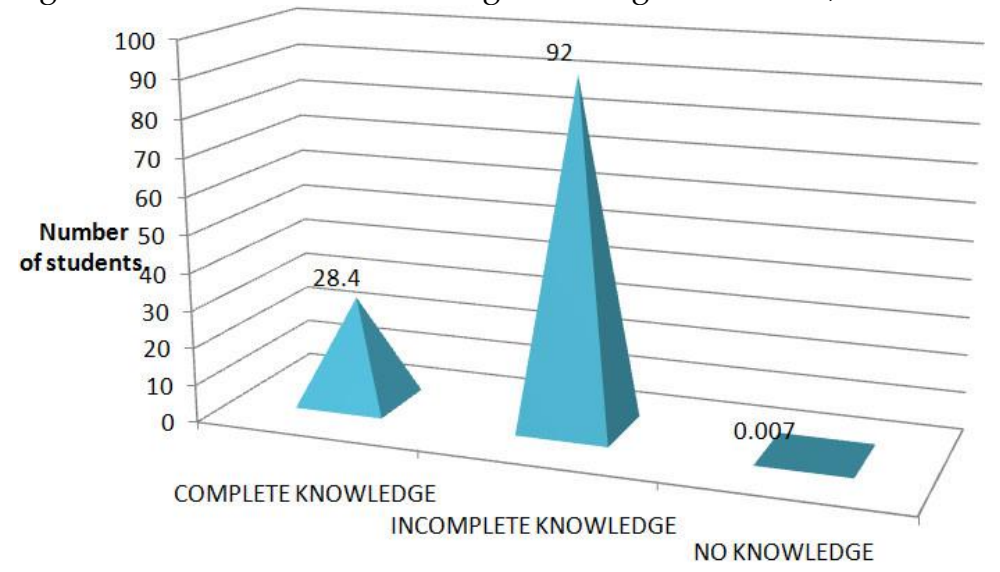

Table 2 Frequency distribution-showing student's perception about sources of transmission of HBV, HCV and HIV (Total number of students 130)

\begin{tabular}{|l|c|c|c|c|c|c|}
\hline Sources of Transmission & \multicolumn{2}{|c|}{ HBV } & \multicolumn{2}{c|}{ HCV } & \multicolumn{2}{c|}{ HIV } \\
\hline & Number of students & $\%$ & Number of students & $\%$ & Number of students & $\%$ \\
\hline Sweat & 28 & 21.5 & 21 & 16.15 & 27 & 20.77 \\
\hline Saliva & 92 & 70.7 & 87 & 66.9 & 83 & 63.85 \\
\hline $\begin{array}{l}\text { Intact skin to skin contact } \\
\text { during examination }\end{array}$ & 13 & 10 & 12 & 9.23 & 16 & 12.31 \\
\hline Bed of the patient & 27 & 20.7 & 28 & 21.53 & 29 & 22.31 \\
\hline Patient's clothes & 29 & 22.3 & 29 & 22.30 & 27 & 20.47 \\
\hline Vomitus without blood & 58 & 44.6 & 49 & 37.69 & 52 & 40 \\
\hline Blood & 120 & 92.3 & 120 & 92.3 & 126 & 96.92 \\
\hline Needle stick injury & 116 & 89.2 & 117 & 90 & 111 & 85.38 \\
\hline Urine & 43 & 33.07 & 40 & 30.76 & 38 & 29.23 \\
\hline Wound dressing & 74 & 56.1 & 69 & 53.08 & 70 & 53.85 \\
\hline Wound & 99 & 76.1 & 99 & 76.15 & 99 & 76.15 \\
\hline Drain tubes fluid & 82 & 63.01 & 77 & 59.23 & 81 & 62.31 \\
\hline Sharing eating utensils & 49 & 37.69 & 49 & 37.69 & 47 & 36.15 \\
\hline Handshake & 11 & 8.46 & 13 & 10 & & 11 \\
\hline Cough & 64 & 49.23 & 69 & 53.08 & 60 & 8.41 \\
\hline Vaginal secretions & 111 & 85.38 & 108 & 83.08 & 117 & 46.15 \\
\hline Semen & 115 & 88.4 & 120 & 92.3 & 114 & 90 \\
\hline Sharing nail cutter, comb, etc. & 103 & 69.2 & 102 & 78.4 & 106 & 87.69 \\
\hline Above table & & & & 81.54 \\
\hline
\end{tabular}

Above table shows different sources of transmission HBV, HCV and HIV diseases. The major sources of transmission are veginal secretions, semen,nail cutter, comb and needles stick injury. 
Figure 2: Sources of transmission of HBV,HCV and HIV

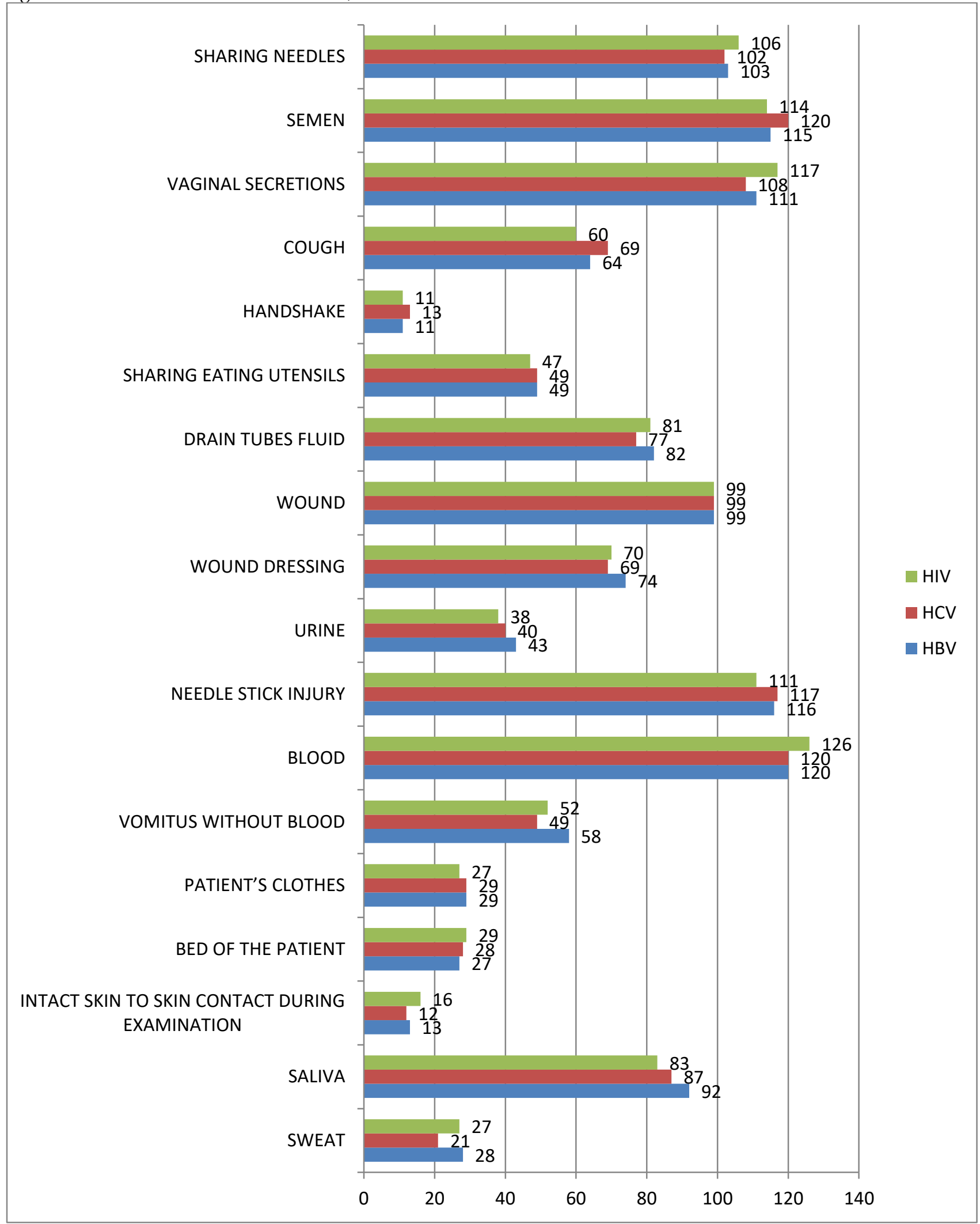


Table 3: Frequency distribution table showing fear among students for examination of patients with HBV, HIV and HCV.(Total number of students are 130)

\begin{tabular}{|c|c|c|c|c|}
\hline DISEASE & \multicolumn{2}{|c|}{ AFRAID } & \multicolumn{2}{c|}{ NOT AFRAID } \\
\hline & No. of students & $\%$ & No. of students & $\%$ \\
\hline HBV, HCV, HIV & 52 & 40 & 78 & 60 \\
\hline
\end{tabular}

Table 3 shows that 40 percent sampling students expressed fear while 60 percent out of 52 students did not express any fear about transmission of HBV, HIV, and HCV diseases while examining the patients.

Figure 3: Fear among students for examination of patients with HBV, HIV, and HCV

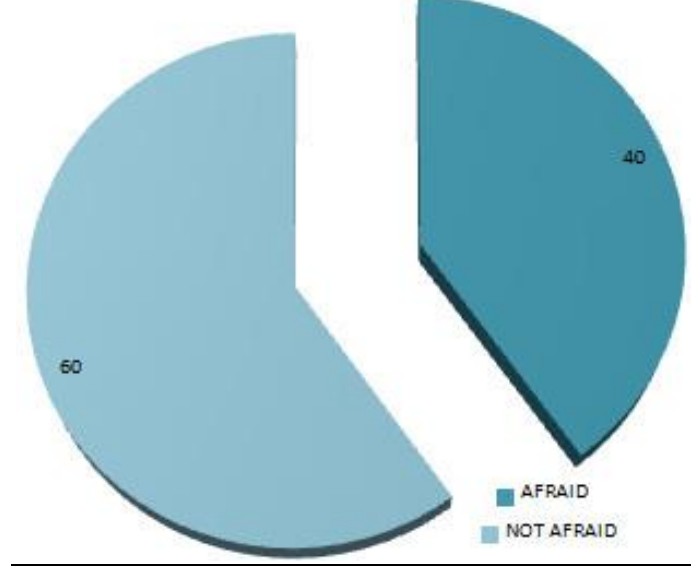

Table 4: Frequency distribution table showing knowledge of students about availability of vaccination against HBV, HCV and HIV (Total number of students are 130)

\begin{tabular}{|c|c|c|c|c|}
\hline DISEASES & \multicolumn{2}{|c|}{ VACCINE AVAILABLE } & \multicolumn{2}{c|}{ VACCINE NOT AVAILABLE } \\
\hline & Number of students & $\%$ & Number of students & $\%$ \\
\hline HBV & 105 & 80.7 & 25 & 19.3 \\
\hline HCV & 55 & 42.3 & 75 & 57.7 \\
\hline HIV & 22 & 16.9 & 108 & 83.1 \\
\hline
\end{tabular}

Table 4 shows that out of 105 students have knowledge about the availability of vaccine while out of $55,42.3$ percent students have moderate knowledge while out of 22 students 16.9 percent have very poor knowledge about it. Similarly, out of 75 students, 57.7 percent have no knowledge about the availability of HCV vaccine, which is shocking. Similarly, out of 108, 83.1 percent students did not have knowledge about the availability of vaccine for treatment of HIV.

Figure 4: Knowledge about availability of vaccine for HBV

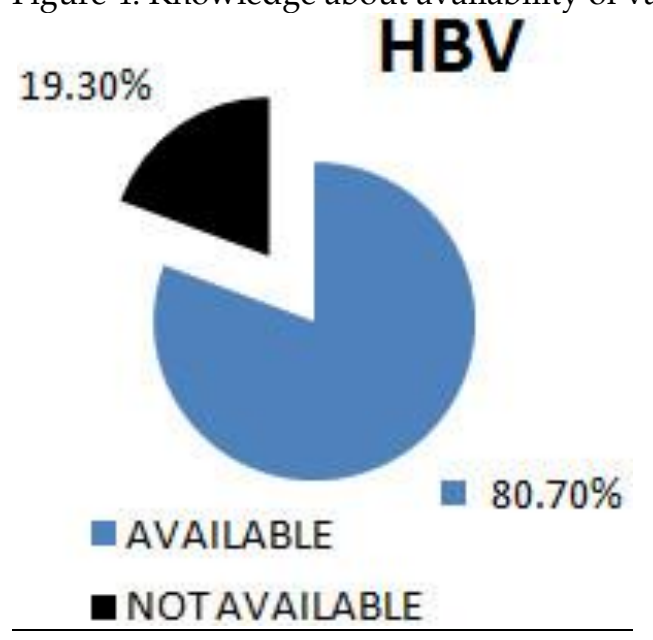


Figure 5: Knowledge about availability of vaccine for HCV

\section{$\mathrm{HCV}$}

\section{- $42.30 \%$}

$57.70 \%$

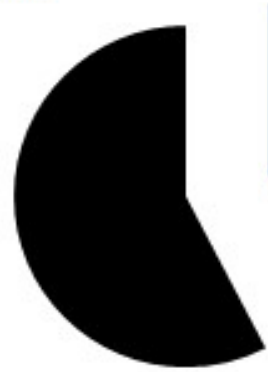

AVAILABLE

NOT AVAILABLE

Figure 6: Knowledge of students about the availability of vaccine for HIV treatment

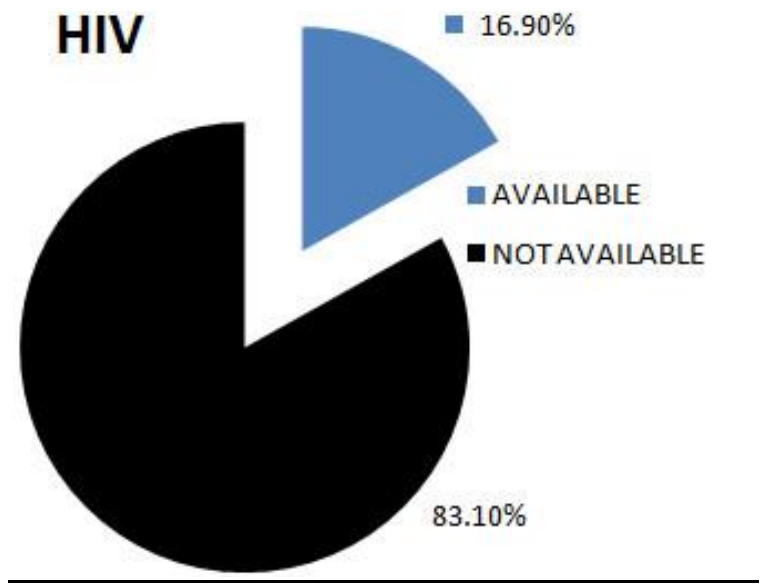

Table 5: Frequency distribution of vaccination status of students against HBV (total number of students are 130)

\begin{tabular}{|c|c|c|c|c|}
\hline DISEASE & \multicolumn{2}{|c|}{ VACCINATED } & \multicolumn{2}{c|}{ NOT VACCINATED } \\
\hline & Number of students & $\mathbf{\%}$ & Number of students & $\%$ \\
\hline HBV & 106 & 81.5 & 24 & 19.5 \\
\hline
\end{tabular}

Table 5 shows that out of 106 sampling group of students, 81.5 percent were vaccinated against HBV while out of 24 students 19.5 percent did not get vaccination as a precautionary measure to protect them from this fatal disease. This shows there careless attitude, which may be dangerous. It also shows the level of unawareness among the students about the fatal effects of HBV.

Figure 7: Vaccination status of students against HBV

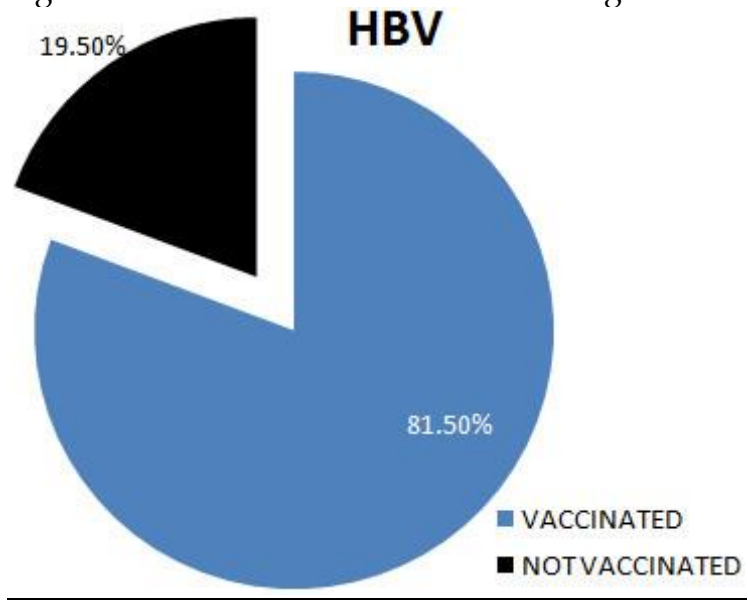




\section{FINDINGS AND RESULTS}

Medical professionals play a very important in disease prevention and treatment. In view of this, it is very important that they should have a sound knowledge about sources, modes of transmission, hereditary patterns, signs, and symptoms and preventive methods of diseases. This is important not only in providing better health facilities to the patients but also protects them from acquiring diseases in clinical settings as many diseases can be contracted through various accidents that may occur during examination of patients for example needle stick injuries, body fluids of patients with certain diseases and so on. Medical students are much more susceptible to such incidents as they are untrained and are usually unaware of the preventive measures that should be taken in this regard.

Many studies have been carried out all over the world to find out the extent of medical students' awareness about various aspects of $\mathrm{HBV}, \mathrm{HCV}$, and HIV. According to a study carried out in Agha Khan Medical University, $90 \%$ of medical students were aware of the fact that each of HBV, HCV and HIV can be transmitted via needle stick injuries18.The same study also indicated that more than $90 \%$ of the medical students who had participated in that survey had received all the three doses of hepatitis B vaccination19.A study conducted by Tehran University of Medical Sciences showed that $87.5 \%$ of the interns who had participated in survey had completed the HBV vaccination schedule. It also showed that only a minority of medical students observed basic safety measures during their training sessions in wards. According to our study in Nishtar Medical College Multan, only 28.4\% students of 3rd year MBBS had complete knowledge about the modes of transmission of HBV, HCV, and HIV. 80.7\% students were aware of the availability of vaccination against $\mathrm{HBV}$ and $81.5 \%$ students who participated in this survey had received all the three doses of hepatitis $\mathrm{B}$ vaccination.

\section{CONCLUSIONS}

From our study, the following conclusions can be drawn:

- The knowledge of most of our medical students about the modes of transmission of HBV, HCV, and HIV is incomplete which is alarming because as future health professionals, they must know modes of transmission of such fatal diseases so that they may protect others and themselves from acquiring the disease from the infected patients.

- Most of the students knew the sources of transmission of these diseases but they also had wrong concepts about some sources that are not involved in the transmission of HBV, HCV, and HIV like intact skin to skin contact etc.

- It has been found that $40 \%$ of the students who participated in this survey were afraid of examining the patients infected with these diseases and they feared they may contract the disease while examining the patients

- Majority of the students had good knowledge about the availability of vaccination and $81.5 \%$ of the students were found to be vaccinated against HBV

\section{RECOMMENDATIONS}

- Medical students should have complete knowledge about routes of transmission of HBV, HCV, and HIV. For these purpose seminars, workshops and special lectures should be arranged for the students.

- All medical students should be vaccinated against HBV because they can acquire these diseases from patients.

- All medical students should follow preventive measures while examining the patients because some viral diseases can be transmitted by needle stick injuries and other accidents that may take place in clinical settings.

- Special sessions providing information about these diseases should be conducted for medical students. Moreover, students should be encouraged to become part of the programs that are directed towards imparting education to the community about these fatal diseases.

\section{REFERENCES}

Asebe G, Ameni G and Tafess K.2014. Ten years tuberculosis trend in Gambella Regional Hospital, South Western Ethiopia. Malaysian Journal of Medical and Biological Research, 1, 18-24.

Awan, A.G. (2014) "Environmental Challenges to South Asian countries," Asian Accounting and Auditing Advancement, V01 3, No.1, 2013: 84-103.

Awan,A.G (2013) Relationship between Environment and Sustainable Economic Development: A Theoretical Approach to Environmental Problems", International Journal of Asian Social Sciences, Vol. 3, No.3, 2013: 741-761.

Batoul Shariati (et al, 2007) Accidental Exposure to Blood in Interns of Tehran University of Medical Sciences, J Occup Health;49;317-321.

Gallo RC (2006). "A reflection on HIV/AIDS research after 25 years". Retrovirology 3: 72. doi:10.1186/1742-4690-3-72. PMC1629027. PMID17054781.

Ganem D, Prince AM.(2004)“Hepatitis B virus infection -- natural history and clinical consequences. N Engl J Med; 350:11181129[Erratum, N Engl J Med 2004; 351:351.]

Georg M. Lauer, M.D., and Bruce D. Walker, M.D. N Engl J Med 2001; 345:41-52 July 5, 2001

Ghafoor A and Khan AA. 2014. Emperical Study about Fears and Misconceptions of Aids and Hepatitis among Medical Students. Malaysian Journal of Medical and Biological Research, 1, 25-34. 
Hoofnagle JH, Doo E, Liang TJ, Fleischer R, LokAS.(2007)“Management of hepatitis B: summary of a clinical research workshop”. Hepatology; 45:1056-1075

Kallings LO :.( 2008)"The first postmodern pandemic: 25 years of HIV/AIDS". J Intern Med, 263 (3): 218-43. Doi: 10.1111/j.13652796.2007.01910.x.PMID18205765.

Lee WM:1997) Hepatitis B virus infection. N Engl J Med, 337:1733-1745.

Lok AS, Heathcote EJ, Hoofnagle JH (2001) "Management of hepatitis B: 2000 - summary of a workshop". Gastroenterology, 120:1828-1853.

Lok AS, Heathcote EJ, Hoofnagle JH. (2001) "Management of hepatitis B: 2000 -- summary of a workshop". Gastroenterology;120:1828-1853

Lok AS, McMahon BJ (2007) “Chronic hepatitis B.”Hepatology; 45:507-539[Erratum, Hepatology 2007; 45:1347.]

Lok ASF, McMahon BJ®2001) “Chronic hepatitis B. Hepatology”, 34:1225-1241.

Maddrey WC:2000)“Hepatitis B: an important public Health issue”. J Med Vol, 61:362-366.

Markowitz, edited by William N. Rom; associate editor, Steven B. (2007). Environmental and occupational medicine (4th Ed.). Philadelphia: Wolters Kluwer/Lippincott Williams \& Wilkins. p. 745. ISBN978-0-7817-6299-1.

Sepkowitz KA (June 2001). "AIDS—the first 20 years."N. Engl. J. Med.344 (23): 1764-72.Doi:10.1056/NEJM200106073442306.

Sharp, PM; Hahn, BH (2011). "Origins of HIV and the AIDS Pandemic". Cold Spring Harbor perspectives in medicine 1 (1): a006841.Doi: 10.1101/cshperspect.a006841. PMC3234451.PMID22229120.

TaimorSaleem (et al, 2010)“Knowledge, Attitude and Practices of medical students regarding NSIs.” JMAP Vol 60 No 2 February, 2010.

Tulu T and Kahissay MH. 2014. Assessment of Multidrug Resistance Tuberclosis Treatment Outcome in St. Petre's Tuberclosis Specialized Hospital, Addis Ababa, Ethiopia. Malaysian Journal of Medical and Biological Research, 1, 97-107.

UNAIDS (2010) "Global Report Fact Sheet".

UNAIDS (2011) "Report on HIV and Aid" pp. 1-10.

Zahan, N. (2013). HIV/AIDS Risk among the Children of Bangladesh. ABC Journal Of Advanced Research, 2(2), 30-43. Retrieved from http://journals.abc.us.org/index.php/abcjar/article/view/4.3\%20Revised 